\title{
EL COMERCIO DE PARTITURAS EN BARCELONA ENTRE 1792 Y 1834: DE ANTONIO CHUECA A FRANCISCO BERNAREGGI
}

\author{
THE BUSINESS OF MUSICAL SCORES IN BARCELONA BETWEEN \\ 1792 AND 1834: FROM ANTONIO CHUECA TO FRANCISCO BERNAREGGI
}

Oriol Brugarolas Bonet

Universidad de Barcelona

\section{Resumen}

Los datos que se presentan en este artículo suponen una primera contribución al estudio del comercio de partituras en Barcelona entre 1792 y 1834 . Se dan a conocer los lugares donde se podían comprar partituras impresas y manuscritas y las personas relacionadas con ese comercio (libreros, constructores de instrumentos, músicos, copistas y pequeños comerciantes no especializados en música). También se detallan el sistema comercial mediante el cual se realizaba la venta (venta directa, por suscripción, intercambio, alquiler, en lotes, en cuadernos o mediante periódicos musicales), el repertorio y, en algunos casos, el precio de la partitura. La intensidad del comercio de partituras, sobre todo a partir de 1814, una vez acabada la guerra de la Independencia, evidencia el alto desarrollo de la actividad y la cultura musical de Barcelona y demuestra que España formaba parte de una red de distribución de partituras europea.

\section{Palabras clave}

Barcelona, comercio partituras, libreros, copistas, impresores, constructores de instrumentos, periódicos musicales, almacenes musicales

\section{INTRODUCCIÓN}

El estudio del comercio de partituras, en tanto que objetos de consumo musical, constituye un aspecto fundamental para conocer la vida musical de una ciudad. Permite obtener información sobre la clase de público al que la música va dirigida, el tipo de repertorio de moda, los cambios que dicho repertorio va experimentando con el paso del tiempo $\mathrm{y}$, en definitiva, resulta una valiosa herramienta para dibujar la importancia y el uso social de la música en una ciudad.

\begin{abstract}
The data presented in this article is an initial contribution to the study of musical score business in Barcelona between 1792 and 1834. It includes information about the places where printed and handwritten musical scores could be purchased as well as about the people involved in this business (booksellers, instrument makers, musicians, copyists and small business owners not specialised in music). It also gives specifics about the commercial system through which the purchases were made (direct sales, subscription, hire, exchange, batches, in notebooks or through music newspapers), the repertoire and, in some cases, the price of the musical score. The intensity of the musical score business, particularly from 1814 , once the War of Independence had ended, is a clear sign of the high development of the activity and the musical culture of Barcelona, and demonstrates that Spain formed part of a European distribution network for musical scores.
\end{abstract}

Keywords

Barcelona, musical score business, booksellers, copyists, printers, instruments builders, music journal, musical warehouses

La vitalidad de la compraventa de partituras impresas y manuscritas que alcanza Barcelona entre 1792 y 1834 es una clara muestra de la intensificación de la producción y el consumo de la música, y asimismo genera mayor disponibilidad de partituras tanto en el entorno más inmediato como en otros países, accesibles para cualquier ciudadano con ciertos recursos, y posibilita el contacto entre el público anónimo y los compositores, sin importar la distancia. La expansión del comercio de partituras corre paralela al desarrollo de la actividad constructiva de instrumentos, del co- 
mercio de instrumentos y de la creación de nuevos espacios de consumo musical. También se relaciona con el avance de una nueva clase social que se ha venido llamando burguesía o clase media acomodada, caracterizada por una situación económicamente holgada y cuya presencia es fundamental en la vida social y cultural de la ciudad, articulándose buena parte de sus relaciones sociales alrededor de la música; por tanto, deviene la nueva consumidora del producto musical.

El presente estudio se centra en un aspecto del comercio musical, el de la compraventa y alquiler de partituras impresas y manuscritas en la Barcelona de 1792 a 1834, y el objetivo es desgranar los mecanismos de funcionamiento del comercio musical centrado en dicho aspecto.

Las fechas escogidas para el presente artículo vienen determinadas por la propia evolución del comercio de partituras en Barcelona. El año 1792 es, en realidad, una fecha aproximada en torno a la cual se tienen ya referencias documentales en relación a la actividad de compraventa de partituras de algún librero barcelonés, como Antonio Chueca. En cuanto a 1834, es el año en torno al cual Francisco Bernareggi se consolida como uno de los almacenistas de música más importantes de la ciudad condal.

\section{ESTADO DE LA CUESTIÓN}

A pesar de su interés, la cuestión del comercio de partituras en Barcelona a finales del siglo XVIII y durante el primer tercio del siglo XIX apenas ha sido abordada por la investigación musicológica española ${ }^{1}$. Son de obligada consulta algunos estudios existentes relacionados con el mundo del comercio musical (el de partituras y el instrumental) centrados sobre todo en otro espacio geográfico, Madrid, realizados por José Carlos Gosálvez², Miguel Ángel Marín ${ }^{3}$, Cristina Bordas ${ }^{4}$, Yolanda Acker ${ }^{5}$, Beryl Kenyon de Pascual ${ }^{6}$, Judith Ortega ${ }^{7}$, Ignacio Susaeta ${ }^{8}$ y Laura Cuervo ${ }^{9}$; asimismo existen trabajos vinculados a la actividad editorial y al comercio de la música en España que tienen gran interés, como el de Begoña Lolo ${ }^{10}$, el de José Carlos Gosálvez ${ }^{11}$, el de Car-

1 BRUGAROLAS BONET (2015): 241-325. 215-258

2 GOSÁLVEZ LARA, 64/7 (Madrid, 1992): 133-137; 2014:

3 MARÍN, 33/2 (Oxford, 2005): 165-177.

4 BORDAS IBÁÑEZ (2004).

5 ACKER, (2007).

6 KENYON DE PASCUAL, 5/2 (Madrid, 1982): 309-323; 6/1-2

(Madrid, 1983): 299-308; 8/2 (Madrid, 1985): 303-321.

7 ORTEGA RODRÍGUEZ (2014): 147-182.

8 SUSAETA (1993).

9 CUERVO CALVO (2012)

10 LOLO, GOSÁLVEZ LARA (2012).

11 GOSÁLVEZ LARA (1995). men García Mallo ${ }^{12}$ y la obra colectiva editada por Màrius Bernardó y Miguel Ángel Marín ${ }^{13}$; igualmente, con relación a los distintos aspectos comerciales y técnicos de la edición musical en Europa, cabe destacar la obra de Rudolf Rasch ${ }^{14}$. En cuanto a las investigaciones que tratan el tema del comercio de partituras en Barcelona, hay que decir que acotan la investigación con fechas posteriores a 1847, sin ahondar en el funcionamiento de la actividad comercial de partituras en Barcelona durante el primer tercio del siglo $\mathrm{XIX}^{15}$.

El presente trabajo pretende, pues, llenar esta laguna; y para ello se ha recurrido al estudio de la documentación del fondo gremial municipal y comercial del Archivo Histórico de la Ciudad de Barcelona (AHCB), la del fondo de la Junta de Comerç de Barcelona y la del fondo musical de la Biblioteca de Catalunya (BC); también se ha consultado el Diario de Barcelona entre 1792 y 1834.

Los datos que aquí se presentan suponen una primera aportación al estudio del comercio de partituras en Barcelona y contribuyen a poner de manifiesto la importancia que esta actividad adquirió a finales del siglo xvIII y durante el primer tercio del siglo XIX y a mejorar el conocimiento de la actividad musical en general de la ciudad condal.

\section{BARCELONA EN EL MERCADO MUSICAL EUROPEO}

Con el Reglamento de Libre Comercio con América de $1778^{16}$, Barcelona se convirtió en la segunda ciudad de España, solo por detrás de Cádiz, en importancia en cuanto al volumen de comercio marítimo y terrestre. Así se lo señala Josep Albert Navarro-Mas, miembro de la Academia de Ciencias y Artes de Barcelona, a Francisco de Zamora, funcionario castellano de viaje por Cataluña entre 1785 y 1790:

Siendo Barcelona, después de Cádiz, el pueblo más comerciante y más mercantil de toda España, ya se deja ver cuán grande ha de ser el comercio terrestre y marítimo que se hace en ella, y así es inexplicable lo que se introduce de frutos y géneros de todas las cuatro partes del mundo, y también es inexplicable los mucho que se extrae de ella, tanto de frutos y géneros extraños y propios como de artefactos de sus manufacturas, y de las

12 GARCÍA MALLO, 60 (Barcelona, 2005): 116-167.

13 BERNARDÓ, MARÍN (2014).

14 RASCH (2004).

15 GARCÍA MALLO, 9 (Madrid, 2002): 7-154. BALDELLÓ

(1943): 173-183.

16 Decreto promulgado por Carlos III que permitió el libre comercio con América sin que se tuviera que pasar por Cádiz. 
de otros países, para toda España, para varios dominios extranjeros y principalmente para la América ${ }^{17}$.

El comercio que se promovió a raíz de esta apertura del espacio marítimo estaba dedicado mayoritariamente a los textiles, en especial de indianas ${ }^{18}$. A partir del desarrollo industrial y comercial surgió una nueva clase social, la burguesía barcelonesa moderna, que impulsó la transformación de la ciudad de Barcelona en un centro industrial preponderante, además de fomentar el desarrollo de la vida cultural y artística de la ciudad. En pocos años, entre finales del siglo XVIII y el primer tercio del siglo XIX, Barcelona ${ }^{19}$ se transformó en una urbe comercial, cosmopolita y bien conectada con Europa y América, receptora de viajeros, comerciantes y de curiosos, y así quedó reflejado en la aparición de nuevas costumbres, en los cambios de las mentalidades y con la adopción de las modas culturales provenientes, sobre todo, de Francia.

Fue en esta Barcelona de cambio de siglo en la que se desarrolló una importante actividad musical, tanto en espacios públicos como privados, propia de cualquier capital centroeuropea $^{20}$; en la que se intensificó la producción y el consumo de la música en todos los niveles sociales ${ }^{21}$; en la que debutaban con rapidez las obras estrenadas en otras ciudades de Europa, como la ópera Nina, o sia la pazza per amore, de Giovanni Paisiello, cuyo estreno mundial fue en 1789, y ese mismo año, también se estrenó en Barcelona ${ }^{22}$; en la que se asentaron constructores de instrumentos musicales procedentes sobre todo de Alemania, Italia, Francia, Suiza y de otras regiones de España, con claros propósitos comerciales $^{23}$; y en la que prosperó un comercio de partituras

17 SOBREQUÉS Y CALLICÓ (1993): 34.

18 Las indianas eran tejidos de algodón estampados con colores llamativos y con motivos inspirados en diseños tradicionales de la India. Las indianas eran utilizadas tanto para la confección de vestidos y complementos, como para la decoración de paredes, según la moda instaurada en Inglaterra y Holanda.

19 Hacia 1800, Barcelona era una de las veinte ciudades europeas que contaba con más de 100.000 habitantes. En LÓPEZ GUALLAR, 11 (Barcelona, 2004): 69-71.

20 BRUGAROLAS BONET (2015): 215-240.

21 VALLUGERA (2013): 1299-1302. BRUGAROLAS BONET, 21 (2011): 83-102.

22 Otros obras que muestran la celeridad con la que debutaban en Barcelona las obras estrenadas en otras ciudades europeas: la ópera de Franceso Gardi La dona ve la fa, que se estrenó en Venecia en 1800 y se ejecutó en Barcelona un año más tarde o bien L'Italiana in Algeri de Rossini, estrenada en mayo de 1813 en Venecia, y en 1815 en Barcelona.

23 Tal es el caso, entre otros, de los italianos Pedro Arnó y Francisco Bernareggi, del flamenco Juan Joseph Esttefentt, de los franceses Louis Boisselot y Antoine Rinaudin, de los alemanes Juan Kyburz y Francisco Otter, y del gerundense Pedro Figueras. Hay que tener en (e instrumentos), llevado a cabo por copistas, constructores de instrumentos, particulares, libreros, y comerciantes no especializados en música, que distribuían partituras, muchas de ellas adquiridas en París y Londres ${ }^{24}$. De este modo, cualquier músico profesional o aficionado instalado en esta urbe y con ciertos recursos estaba informado de las principales novedades musicales que se sucedían en Europa ${ }^{25}$ y tenía un fácil acceso a todo tipo de material musical tanto de producción local como de importación (instrumentos, partituras impresas y manuscritas, métodos y tratados musicales...). Lo que facilitó y permitió aproximar y conectar culturalmente algunas de las ciudades europeas más importantes del momento fue, sin duda, la actividad comercial de algunos libreros. Tal es el caso de Juan Francisco Piferrer ${ }^{26}$, uno de los libreros e impresores más importantes de Barcelona, que, entre los años noventa del siglo XVIII y el primer tercio del siglo XIX, vendió partituras y mantuvo un fluido, constante e intenso contacto comercial con otros libreros de ciudades españolas (Valencia, Sevilla, Cádiz, Madrid, Bilbao y Salamanca) y del resto de Europa (Ginebra, Lyon, Venecia, Milán, París, Lisboa y Amberes).

Barcelona se convirtió así, a lo largo del primer tercio del siglo XIX, en una plaza imprescindible en el comercio musical español y europeo $\mathrm{y}$, tal como queda reflejado en los numerosos anuncios del Diario de Barcelona referidos a la compraventa de partituras, pasó "a formar parte de una red de distribución de partituras europea desarrollada por los principales editores y vendedores de música" ${ }^{27}$.

cuenta que aparte de la importante actividad portuaria de Barcelona (que le confería la posibilidad de comerciar con las colonias españolas de América) y su ubicación privilegiada respecto a Europa (a pocos días de la frontera con Francia e incluso con Italia), otro factor determinante que permitió que se instalaran profesionales de la construcción de instrumentos musicales en Barcelona fue la aprobación de dos medidas reformistas, la Real Orden de 30 de agosto de 1797 y la Real Cédula de 4 de marzo de 1798: la Real Orden permitía a cualquier artesano o fabricante extranjero establecerse, siempre que probara su aptitud ante la Junta General o ante sus subdelegados, los intendentes; y la Real Cédula sustituía los largos años de aprendizaje y oficialía por un rápido examen.

$24 \mathrm{Tal}$ como se puede leer en diversos anuncios. Por ejemplo, Diario de Barcelona, 3-11-1816: "En la librería de Joseph Sellent y Gibert, calle de la Espasería, se hallarán de venta varios cuadernos de música, como grandes sonatas, variaciones, contradanzas, todo para piano-forte y algunos grandes dúos para flautas y violines, todo impreso en París".

25 Gracias a los siguientes diarios, impresos en la ciudad de Barcelona: la Gazeta de Barcelona; el Caxon de Sastre Cathalan; Diario curioso, histórico, erudito y comercial; y el Diario de Barcelona.

26 Juan Francisco Piferrer (1771-1848). Según el catastro de impresores libreros de 1801, tenía casa y tienda en la plaza del Ángel. Para hacerse la idea de la importancia del negocio de Piferrer, en sus almacenes albergaban en 1794 alrededor de 255.678 volúmenes de libros y ejemplares de comedias. Véase BURGOS, PEÑA, 6 (1987): 181-216.

27 MARÍN, LEZA (2014): 441. 


\section{PRIMERA ETAPA (1792-1808): LAS PRIMERAS INICIATIVAS EN EL COMERCIO DE PARTITURAS EN BARCELONA}

Una de las primeras referencias documentales de compraventa de partituras en Barcelona ${ }^{28}$ es el anuncio de noviembre de 1792 del librero Antonio Chueca, en el que vendía "toda la música y poesía completa de una ópera y un clave romano bien acondicionado en la Rambla, casa de Antonio Chueca, librero, frente a la de la Virreina del Perú" ${ }^{29}$. Tal como se advierte por el creciente número de anuncios referentes a la compraventa de partituras en el Diario de Barcelon $a^{30}$ y por el progresivo aumento de comerciantes dedicados al comercio musical, a partir de $1792^{31}$ se intensifica el comercio de partituras, espoleado por el incremento de la demanda por parte de la burguesía emergente y las clases medias acomodadas; estas se convirtieron en los principales consumidores del producto musical e hicieron girar buena parte de los actos sociales sobre la música en cualquiera de sus manifestaciones, transformando así los acontecimientos sociales, incluso los más insignificantes, en eventos culturales de diversa importancia. De aquí surgió la figura del aficionado o amateur, que acabó siendo el motor de cambio de la producción y el comercio musical ${ }^{32}$ puesto que los aficionados acudían regularmente a los conciertos, participaban en tertulias musicales en los salones privados, se suscribían a periódicos musicales y compraban partituras (mayoritariamente transcripciones para piano de óperas conocidas), instrumentos y métodos para el aprendizaje musical.

En este contexto, hay que tener en cuenta el papel que jugó el vendedor de partituras, encarnado en la figura del librero, del constructor de instrumentos, del copista y del particular (músicos profesionales, carpinteros, militares, entre otros), todos ellos piezas ineludibles en el engranaje del comercio de partituras impresas y manuscritas, ya que

28 La primera mención conocida de venta de partituras en Barcelona es el anuncio del 4 de julio de 1780 en la Gaceta de Madrid: "Seis sonatas para forte piano, que pueden servir para clavicordio, compuestas por Don Joseph Ferrer, organista de la catedral de Pamplona [...]. Se hallará a 6 rs. en Madrid en casa de Esparza, puerta del Sol [...]. En Barcelona en la de Juan Alsinas maestro de claves". No se han hallado otras referencias documentales a lo largo de la década de 1780 referentes a la compraventa de partituras en dicha ciudad.

29 Diario de Barcelona, 21-11-1792.

30 De media, cada año hubo: 3,1 anuncios referentes al comercio de partituras, entre 1792 y 1808; 2,3 anuncios referentes al comercio de partituras, entre 1808 y 1814 ; y 4,1 anuncios referentes al comercio de partituras, entre 1814 y 1834. En: BRUGAROLAS BONET (2015): 286-297.

31 Año de la fundación del Diario de Barcelona.

32 BORDAS IBÁÑEZ (2004):167-173. posibilitaron la accesibilidad de la música a un conjunto más amplio de la sociedad y propiciaron el acercamiento entre el creador y el último eslabón en la cadena de consumo: el público (comprendido por la audiencia, músicos aficionados, profesionales de la música)

Por tanto, los protagonistas en la compraventa de partituras impresas y manuscritas durante esta primera etapa (1792-1808) fueron libreros no especializados en música, copistas, comerciantes en general, personas particulares y algunos constructores de instrumentos.

\section{Libreros}

En cuanto a los libreros, se estima que de un total de 26 libreros activos en la ciudad condal en $1800^{33}$ fueron al menos siete los que incorporaron a su negocio del libro la compraventa de partituras ${ }^{34}$ : Antonio Chueca, en la Rambla; Juan Francisco Piferrer, en la plaza del Ángel; Tomás Gorchs, en la calle Boria; Francisco Roca, en la plaza de la Cucurulla; Francisco Generas, en la calle Bajada de la Cárcel; Mateo Echterling, en la calle del Call; y Francisco Ifern y Oriol, en la calle Agullers. De todos ellos, cabe destacar la actividad comercial, en el campo de la música, del librero e impresor Tomás Gorchs ${ }^{35}$ por la asiduidad con que inserta anuncios en el Diario de Barcelona ${ }^{36}$ referentes a la com-

33 Consejo de maestros libreros, Archivo de Protocolos Notariales (AHPNB), Miquel Vilamala (notario núm. 1151), vol. 15, fols. 4-17. 34 Datos extraídos del Diario de Barcelona. A modo de ejemplo, son interesantes los siguientes anuncios referidos a los libreros que incorporaron partituras a sus negocios: "En la librería de Francisco Generas, baixada de la Cárcel, se hallan de venta a precios equitativos varios conciertos de música para flauta, cuartetos y quintetos de los más célebres autores", en Diario de Barcelona, 3-11-1809; "Se abre subscripción a la obra de cantollano y órgano intitulada El práctica cantar en el misterio de la iglesia, compuesto por Don Daniel Traveria, capellán de S. M. Maria de Austria [...] y a una colección de sonatas para Forte piano y órgano de varios autores [...]. Se subscriben en la librería de Mateo Echterling, en la calle del call", en Diario de Barcelona 10-1-1799.

35 Tomás Gorchs (1777-1828), librero e impresor activo ya desde finales del siglo xviII. Según el Diario de Barcelona, el 29 de enero de 1819 estableció un gabinete de lectura en su librería: "A fin de que una ciudad tan populosa como esta no carezca de un objeto utilísimo y muy deseado, se advierte: que desde hoy en adelante se abre una suscripción para dejar libros, al moderado estipendio de 10 rs. mensuales, con el objeto de que los aficionados a la lectura encuentren a poca coste en que pasar el tiempo con alguna distracción instructiva y laudable". Tomás Gorchs murió en 1828 y la viuda y los hijos de Gorchs (Tomás y Ceferino) continuaron con el negocio.

36 A modo de ejemplo, son interesantes los siguientes anuncios: "En la librería de Tomás Gorchs, en la Boria, se hallarán los libros siguientes: [...] Música: cuatro marchas nuevas alusivas a las conquistas de Viena, Múnich y Ulma por S. M. Napoleón I, a 6 rs. vn. para guitarra y a 5 rs. vn. para flauta; asimismo papel rayado para música de todas clases y libretas para el mismo intento", en Diario de Barcelona, 19- 
praventa de partituras y de material musical. Probablemente Gorchs, al igual que otros libreros (como Francisco Roca) $)^{37}$, se especializó en un determinado repertorio, de carácter popular (seguidillas, contradanzas, boleros, fandangos) para instrumentos en plena expansión y con una importante presencia social, como eran el piano, la guitarra y la flauta. Igualmente, en esta primera etapa, Gorchs comercializó en mayor número las partituras manuscritas que las impresas, dado que "el sistema del comercio de partituras manuscritas evitaba los elevados costes asociados a la impresión y distribución de publicaciones, al tiempo que permitía adaptarse mejor a la demanda real de los distintos géneros y a las necesidades de los distintos perfiles de aficionados" ${ }^{" 38} \mathrm{y}$, por tanto, un tipo u otro de soporte repercutía en el precio final de la partitura.

En el análisis de los precios del material musical que vendía Gorchs se desvela que abunda la venta de partituras manuscritas (las de precio más moderado, entre 5 y 6 reales de vellón), más accesibles a la mayoría de aficionados; en cambio, escasea el comercio de partituras impresas, como la anteriormente referenciada del Diario de Barcelona de junio de $1806^{39}$, dado el elevado precio al que se vendían (a 12 reales de vellón), casi el doble que las manuscritas. Al comparar el precio de las partituras impresas, que en este caso vendía Tomás Gorchs, con diferentes objetos culturales del momento se puede apreciar lo inalcanzables que aquellas podían llegar a ser para la gran mayoría de barceloneses: la entrada más barata para el Teatro de la Santa Cruz de Barcelona, hacia 1805, costaba entre 2 y 3 reales de vellón ${ }^{40}$; el Tratado de recreación instructiva sobre la Danza, su invención y diferencias, un libro encuadernado en rústica, se vendía en la librería Piferrer, hacia 1794, por 5 reales de vellón $\mathrm{n}^{41}$; y Particularidades de la vida y muerte de un pretendido filósofo

5-1806; "En la librería de Tomás Gorchs, en la Boria, se hallarán los libros siguientes usados [...] y la música siguiente: un minué con su contradanza y unas seguidillas boleros acompañadas de guitarra, a 6 rs. vn., un nocturno y un rondó para flauta y guitarra a 12 rs. vn.”, en Diario de Barcelona, 8-6-1806.

37 Tal como se advierte en los anuncios insertados en el Diario de Barcelona por Francisco Roca (1776-?), se habría especializado en música de cámara o en música para instrumentos solistas muy difundidos, como el piano, la guitarra o la flauta.

38 Los investigadores José Carlos Gosálvez y Miguel Ángel Marín apuntan que el comercio de partituras manuscritas fue mayor que el comercio de partituras impresas. Según Marín, la elección del soporte dependía de factores como las posibilidades técnicas de impresión, el uso y función de los géneros musicales y las características del mercado de cada país. Véase MARÍN, LEZA (2014): 439-552.

39 "Un nocturno y un rondó para flauta y guitarra a 12 rs. vn."; en Diario de Barcelona, 8-6-1806.

40 Diario de Barcelona, 4-4-1805.

41 Diario de Barcelona, 10-3-1794. moderno, un libro encuadernado en rústica, se vendía en la librería Sierra y Martí, hacia 1799, por 6 reales de vellón ${ }^{42}$.

\section{Copistas}

Los copistas, profesionales trabajaban exclusivamente en la edición manuscrita, también tomaron parte relevante en el comercio de partituras en Barcelona a lo largo de la primera etapa. El número de anuncios insertados por copistas en el Diario de Barcelona para ofrecer sus servicios difiere de una etapa a otra, siendo más elevado entre 1790 y 1808, y se han contabilizado seis copistas en esa primera etapa, mientras que las dos etapas siguientes (1808-1814 y 1814-1834) apenas suman, entre las dos, cinco copistas activos. Estos datos corroboran que en los primeros años la demanda y la producción de ediciones manuscritas era creciente, y que la figura del copista todavía ejercía un papel importante como difusor de piezas musicales para el uso profesional y para el uso didáctico. Como señala Cuervo, "el oficio de copista estaba todavía sujeto a las costumbres gremiales imperantes en España durante esa época [...]. Una vez capacitado para llevar a cabo su profesión, el copista solía ponerse al servicio de una librería, casa noble o Casa Real [o de algún teatro de ópera]. Las librerías los contrataban para la realización de copias por encargo, generalmente de forma puntual. Con el transcurso del primer tercio del siglo XIX, aunque la demanda del manuscrito disminuyó, todavía existieron profesionales comprometidos con el desempeño de este oficio" ${ }^{43}$. Por tanto, la labor del copista contribuyó al desarrollo de la actividad musical barcelonesa, puesto que la copia manuscrita permitió eludir los costes, aún excesivamente elevados, de la impresión y la distribución de las publicaciones ${ }^{44}$, y pudieron venderse estas partituras a unos precios más accesibles para la mayoría de los aficionados. Asimismo, Cuervo señala que el precio de las obras manuscritas para guitarra o piano solo, dos instrumentos de una elevada demanda social, era mucho más elevado que si las obras fueran para otro instrumento con menos demanda ${ }^{45}$. Pese a que la mayoría de los copistas activos en esta primera etapa todavía permanecen en el anonimato ${ }^{46}$, se sabe que Ángel Valli fue el copista del Teatro de la Santa Cruz, al menos desde 1800 hasta 1805, que vivía en la calle de Lancaster, y que también vendía instrumentos

42 Diario de Barcelona, 7-4-1799.

43 CUERVO CALVO (2012): 108-109.

44 Véase nota al pie 36.

45 CUERVO CALVO (2012):111.

46 Por ejemplo: "En la oficina del Diario darán razón de un músico de los Suizos de Schwaller que copia perfectamente toda música y con equidad", en: Diario de Barcelona, 22-12-1795. 
musicales ${ }^{47}$; asimismo se tiene constancia de la actividad del copista Lanqueña, desarrollada a finales del siglo XVIII ${ }^{48}$. Los copistas profesionales, aunque estuvieran trabajando para alguna institución (como Valli), también lo hacían para particulares (seguramente como Lanqueña): copiaban obras por iniciativa propia (eligiendo partituras de moda que luego esperaba vender), o bien por encargo, ya fuera de clientes o a petición de algún librero (que solicitaba copias de obras de su catálogo para sus propios clientes).

\section{Comercios no especializados en música}

Otros vendedores de partituras en este primer período fueron los comerciantes que regentaban establecimientos sin relación con la música, pero que vieron en la compraventa de partituras un negocio al alza. La tienda de quincalla de la plaza del Ángel fue uno de los comercios ajenos al ámbito musical más activos en la venta de partituras, según se deduce analizando el Diario de Barcelona: "En la tienda de quincalla de la plaza del Ángel, se continúa la venta de piezas de música vocales e instrumentales, las varias sonatas para el fuerte-piano y la entera colección de las obras para el relatado instrumento de W. A. Mozart"49; además, dado el elevado coste que tenía la música impresa, esta quincallería ofrecía la posibilidad de alquilar partituras ${ }^{50}$, una práctica que facilitaba a los aficionados el poder alternar de obra con frecuencia a un coste bajo. También se podían adquirir partituras en comercios tan peculiares como el del cobrero Joseph Jufiant $^{51}$, o el del papelero Francisco Barberí ${ }^{52}$.

\section{Tiendas-taller de los constructores de instrumentos}

Igualmente fueron protagonistas en el comercio de partituras impresas y manuscritas los constructores de instrumentos. Hacia 1800, dos guitarreros, Francisco España

47 "El que quiera comprar un oboe y una media flauta, ambos instrumentos usados, de buen autor, y que se darán a precio conveniente, acuda a casa de Ángel Valli, copista de las óperas", en Diario de Barcelona, 2-5-1800. "Ángel Valli, copista de las óperas de este Teatro, tiene para vender un buen violín y una violeta [...]. Vive en la calle de Lancaster, al lado de un dorador, segundo piso", en Diario de Barcelona, 28-9-1805.

48 "Quien tuviere que dar a copiar algunas piezas de música acuda a la casa de la Sra. Margarita Balma, donde vive el señor Lanqueña, que tiene dicha habilidad”, en Diario de Barcelona, 26-1-1797.

49 Diario de Barcelona, 28-9-1806.

50 Diario de Barcelona, 20-10-1805.

51 Diario de Barcelona, 18-3-1808.

52 Diario de Barcelona, 11-4-1805.
Primero $^{53}$ y Valentín Fabrés ${ }^{54}$, para darse a conocer y motivar al público a visitar y comprar en sus tiendas-taller de instrumentos de fabricación propia y, en definitiva, ampliar su clientela musical, incorporaron a sus respectivos negocios la venta de otros instrumentos (salterios, pianos y violines), la venta de partituras ${ }^{55}$ y la venta de cuerdas para violín y guitarra y el llamado papel rayado. Cabe decir que en ninguno de los anuncios cotejados de estos dos constructores aparece la palabra almacén, sino tienda o taller. Estos pequeños talleres-tienda, que disponían, tal como se ha visto, de un amplio surtido de productos musicales, fueron los antecesores de los grandes almacenes de música que empezaron a desarrollarse a partir de la década de $1830^{56}$.

\section{Vendedores particulares}

Finalmente, hay que tener en cuenta a los particulares en el negocio de la venta de partituras impresas y manuscritas, es decir, todas esas personas que solían vender o comprar desde sus domicilios particulares. El estudio de los anuncios en el Diario de Barcelona insertados por parte de estos ha permitido distinguir dos grupos de vendedores particulares:

53 Se añade Primero puesto que hubo tres guitarreros llamados Francisco España de la misma familia. De Francisco España Primero se sabe que se dedicó a la construcción de guitarras y al comercio musical entre 1758 y 1817; tenía la tienda-taller en la calle Escudellers núm. 2 de Barcelona. Francisco España Tercero es hijo de Francisco España Primero y estuvo activo en la construcción de instrumentos y en el comercio musical desde 1820 hasta 1877, año en el que fallece. En PELLISA Y PUJADES (2013): 258-260. Véase también BRUGAROLAS BONE, (2015): 250-263

54 Caixa amb documents varis del gremi de fusters, Archivo Histórico de la Ciudad de Barcelona (AHCB), 37-73. Llibre del clavari, ACHB, 37-19, p. 120r. Hay que añadir que Valentín Fabrés, constructor de guitarras, también se dedicó al comercio musical, pues vendía guitarras y otros instrumentos de música, partituras y material musical. Este constructor-comerciante estuvo activo en el comercio de instrumentos y en la construcción de guitarras en Barcelona entre 1800 y 1823. Véase BRUGAROLAS BONET (2015): 250-255.

55 He aquí dos ejemplos de anuncios referentes a la venta de partituras insertados por estos dos constructores de guitarras: "Quien quisiere comprar un violín y una partida de música para dicho instrumento de los mejores autores, como Hayden y Viotti, acuda a Francisco España, guitarrero, calle de los Escudellers, cerca del Palao", en Diario de Barcelona, 20-10-1805. "En la tienda de Valentín Fabrés, guitarrero, calle de los Escudellers, se halla de venta un espinetón y música instrumental y vocal para vender, y se dará con la equidad posible", en Diario de Barcelona, 4-9-1805.

56 A partir de 1820, algunos pequeños talleres-tienda, como el de Francisco España Tercero y el de Francisco Bernareggi, dieron paso a las tiendas especializadas en músicas de mayor capacidad comercial, es decir, aquellos establecimientos comerciales mejor surtidos y de abultado volumen de negocio, en los que se vendía todo tipo de mercancías relacionadas con la música: instrumentos nacionales y extranjeros, accesorios, partituras, libros y papel pautado. 
por un lado están los particulares anónimos, de los que no se sabe nada (ni tampoco del comprador), ya que en estos casos el Diario de Barcelona actuaba como intermediario entre particulares ${ }^{57}$; y por otro lado están los particulares conocidos, que solían ser músicos, y de los que se conoce el nombre, la profesión y habitualmente la dirección ${ }^{58}$.

\section{Fórmulas de venta}

La venta directa fue el sistema más habitual de distribución de partituras en Barcelona, igual que en Madrid y en otras ciudades europeas: el cliente recibía el material musical en el momento en que se efectuaba el pago por dicho producto. Aun así, se adoptaron también otras fórmulas o estrategias para favorecer la venta de partituras, como el alquiler de partituras ${ }^{59}$. Dado su bajo coste, el alquiler permitía el acceso a la partitura a bolsillos menos acaudalados, y también favorecía el acceso a un surtido de piezas más amplio a quienes gustaban de alternar de obra con frecuencia. La suscripción fue otra fórmula implantada por los libreros para aumentar las ventas: esta modalidad proporcionaba ingresos por anticipado, que aliviaban la inversión previa y disminuían el riesgo de pérdidas y, por tanto, permitía ajustar los precios, de manera que se atraía a un público potencialmente más amplio. Un ejemplo es el librero Mateo Echterling, que en 1799 ofrecía suscripción a una colección de sonatas para piano de varios autores ${ }^{60}$.

\section{Repertorio}

En Barcelona, en esta primera etapa, podían adquirirse con facilidad obras manuscritas o impresas de varias dece-

57 Dos ejemplos: "En la calle de los Tallers, entrando por la Rambla, casa núm. 66, enfrente de un beco, se hallarán de venta la música siguiente: sonatas de violín, duetos, tríos, cuartetos y sinfonías de los autores Cambini, Lidel, Boquerini, Chiabran, Sabatini, Jomelli y otros modernos", en Diario de Barcelona, 15-8-1796; y "El que quisiera comprar a precio equitativo las piezas de música siguientes: el dueto $O$ momento fortunato del maestro Paisiello; Aria Se tu m'enganerai del maestro Tozzi; el terceto Scaciame il sonno del dicho Tozzi; la cavatina $L a$ sorte mia Tirana del maestro Masolini; acuda al despacho principal de este Diario que le dirán el dueño", en Diario de Barcelona, 17-8-1801.

58 Dos ejemplos: "En casa de Joseph Guasch, músico de Sta. María del Mar, que vive en los Mirallers, núm. 6, se hallarán libritos manuales para principiantes de canto llano y libritos de todos los toques de guerra para toda la infantería de S. M.”, en Diario de Barcelona, 8-11801; y "Luis Gambino, profesor de violín, se propone dar lecciones a cualquier sujeto que gustare aprender a tocar dicho instrumento [...]; tiene además para vender una suficiente colección de música de los mejores autores, como son Haydn, Mozart, Viotti, etc., por lo perteneciente a sinfonías, quintetos, cuartetos, tríos, dúos; vive en la plaza del Borne, enfrente del boticario del rey", en Diario de Barcelona, 3-10-1802.

59 Diario de Barcelona, 20-10-1805.

60 Diario de Barcelona, 10-1-1799. nas de autores extranjeros y algunos nacionales, y de formaciones instrumentales y géneros musicales muy diversos.

El repertorio más habitual y que más se vendía era el generado para un único instrumento, sobre todo, por el piano, la flauta, el violín y la guitarra, y para formaciones de cámara, en especial, dúos, tríos, algún cuarteto y algún quinteto $^{61}$.

La música de cámara, la sinfonía y la música popular (este último grupo representado por obras como seguidillas, boleras y fandangos) fueron géneros muy demandados en el comercio de partituras, así como lo fue el género religioso, puesto que, tal como señala Marín, "ninguna empresa resultaba tan lucrativa como el comercio de libros de canto llano en un país plagado de instituciones eclesiásticas que se extendían por las vastas posesiones de las Indias"62.

En cuanto a los autores que más se vendían, según el Diario de Barcelona, fueron Mozart (sonatas para piano y música de cámara); Haydn (no se especifican las piezas); Pleyel (dúos, tríos y cuartetos); Pergolesi (el Stabat Mater) y algunas de las sonatas para pianoforte de Travería; arias de óperas para voz y piano (y arreglos de estas para flauta y piano o guitarra y piano) de Piccinni, Anfossi, Zanetti, Cimarosa, Jomelli, Tozzi y Paisiello; y música de cámara de Viotti, Neubauer, Devienne, Kozeluch, Cambini y Boccherini. En definitiva, el repertorio recogía piezas de música atractiva y de moda que estaba dentro de la línea demandada en las reuniones sociales de finales del XVIII y principios del XIX.

\section{SEGUNDA ETAPA (1808-1814): EL COMERCIO DE PARTITURAS DURANTE LA GUERRA DE LA INDEPENDENCIA}

La situación de inestabilidad social y económica a la que se vio sometida Barcelona durante la guerra de la Independencia, que estuvo ocupada desde el 20 de febrero de 1808 hasta el 24 mayo de 1814, tuvo evidentes repercusiones en el consumo musical y en el comercio en general ${ }^{63}$. El Diario de Barcelona así lo refleja por omisión, puesto

61 Véanse los siguientes anuncios referentes a las formaciones instrumentales y a los compositores de las obras que se vendían: Diario de Barcelona, 15-8-1796, 4-7-1799, 4-4-1800, 3-10-1802, 28-11-1804 y 28-9-1806.

62 MARÍN, LEZA (2014): 445-446.

63 Con la guerra, se suspendieron numerosos negocios (algunos comerciantes, por ejemplo, trasladaron el negocio durante un tiempo a Palma de Mallorca; otros simplemente cerraron) y las condiciones de vida y de trabajo de los que se quedaron no fueron precisamente fáciles. Tampoco el ámbito cultural escapó a los rigores de la guerra. Es bien conocido el caso del músico Ramón Carnicer i Batlle (1789-1855), que en 1808 se vio obligado a huir a Mahón, donde permaneció hasta 1814 trabajando como organista y profesor de canto. 
que son escasas las noticias referentes a la música ${ }^{64}$; $\sin$ embargo, llama la atención lo moderado del descenso de la actividad de compraventa de partituras si se compara con algunas actividades musicales, como la construcción, la compraventa y el alquiler de instrumentos o la demanda de profesores de música y conciertos públicos y privados $^{65}$. Posiblemente, el hecho de que el Teatro de la Santa Cruz permaneciera cerrado durante un año y medio, entre abril de 1809 y agosto de 1810 , impulsó la compraventa de partituras entre aquellos aficionados o intérpretes que tenían la intención de continuar con la actividad musical al menos en los espacios privados y en los semipúblicos (como el salón principal de la sede del Gremio de los Veleros, el del Gremio de los Zapateros o el del Gremio de los Taberneros).

El número de comerciantes de partituras impresas y manuscritas en este período se redujo drásticamente, y solo se mantuvieron activas las tiendas no especializadas en música y los particulares, entre los cuales intermediaba el Diario de Barcelona: "Quien quiera comprar el célebre Stabat Mater de Haydn, cada voz e instrumento separado, lo hallará en casa Eduardo Llosas, carpintero, plaza de Junqueras" ${ }^{\prime 6}$. He aquí otros ejemplos:

En la casa de este periódico se dará razón de quién tiene para vender una porción de espartitas de música, que contienen las diversas arias siguientes: Misera me!, de F. Zanetti; Io non so amor tu sei, de M. Montellari; Non mi laguo delles arte, de Pascual Anfossi; deh! Tirvola del mio seno, de Nicolas Piccini ${ }^{67}$.

Se vende en la casa de este diario música instrumental: La batalle d'Austerlitz a gran orquesta por Jadin, miembro del conservatorio; 2 sinfonías concertantes para flauta, oboe, trompa por Devienne; otra sinfonía del mismo para flauta, clarinete y trompa; 3 conciertos de clarinete

64 El número total de anuncios relacionados con la música en la primera etapa (1792-1808) es de 355 (con una media de 22,5 anuncios por año), mientras que entre 1808 y 1814 es de 91 anuncios (con una media de 11,2 anuncios por año). No se han incorporado al cómputo total los anuncios musicales referentes a las programaciones y carteleras del Teatro de la Santa Cruz, del Gran Teatro del Liceo y de las capillas de música de las iglesias barcelonesas. Véase BRUGAROLAS BONET (2015): 247-248.

65 Por ejemplo, entre 1792 y 1808 la media anual de anuncios referentes al comercio de partituras es de 2,4, mientras que entre 1808 y 1814 es de 1,9. En cambio, la media anual de anuncios de constructores de pianos en las mismas fechas pasa de 2,25 a 0,87: el descenso es mucho más marcado. Del mismo modo, los anuncios referentes al comercio de instrumentos pasan de una media anual de 4,75 anuncios a una de 1,25. En BRUGAROLAS BONET (2015): 286-295.

66 Diario de Barcelona, 4-9-1814.

67 Diario de Barcelona, 22-5-1808. por Blasius; el último concierto de flauta de Hugot; 2 conciertos de flauta de Hoffmeiffer ${ }^{68}$.

Aunque no se advierte la referencia de la actividad de ningún copista, los anuncios en el Diario de Barcelona relativos a venta o a fabricación de papel pautado despejan cualquier duda acerca de la importancia de la producción de partituras manuscritas en este período. Por ejemplo: "En la tienda de quincalla de la viuda Barberí, calle dels Boters, se vende [...] papel rayado para música" ${ }^{\prime 9}$.

La forma en que habitualmente se realizaba la venta de partituras en esta segunda etapa fue la venta directa, como en la primera etapa. De hecho, no se ha podido documentar otra forma de venta: ni por suscripción ni por carta ni por cuadernos.

El repertorio de las piezas que aparecen en los anuncios de compraventa de partituras se compone principalmente de fragmentos de óperas de autores franceses e italianos y música de cámara de autores alemanes, como Pleyel y Mozart, todo ello junto con el repertorio que en ese momento se programaba en el Teatro de la Santa Cruz, dirigido por los franceses Dacosta y Vicherat: óperas de autores franceses, como Pierre-Alexandre Monsigny, con la ópera La Belle Ar$\operatorname{senne}^{70}$, Gétry, Champein, Pierre Gaveaux, con la ópera $L e$ diable en vacances ou La suite du diable couleur de rose $e^{71}$, y Dalayrac, y algunas arias sueltas de autores italianos, como Cimarosa y Tozzi.

\section{TERCERA ETAPA (1814-1834): INTENSIFICACIÓN DEL COMERCIO DE PARTITURAS A MANOS DE LIBREROS, COMERCIANTES ESPECIALIZADOS EN MÚSICA Y PARTICULARES}

Las consecuencias que tuvieron la guerra de la Independencia y el posterior reinado de Fernando VII para España fueron muy adversas: primero, por la completa desorganización del país acarreada por el conflicto, por los exilios, las emigraciones y los encarcelamientos que sufrie-

68 Diario de Barcelona, 22-1-1814. El texto original es: «Musique instrumentale a vendre au bureau de ce Journal: La batalle d'Austerlitz à grand orchestre par Jadin, membre du conservatoire; 2 symphonies concertantes pour flûte, hautbois, cor et basson par Devienne; autre symphonie du même pour flûte, clarinete et basson; 3 concerto de clarinete par Blasius; le dernier concerto de flûte par Hugot; 2 concerto de flûte par Hoffmeiffer».

69 Diario de Barcelona, 17-1-1813.

70 Diario de Barcelona, 19-10-1810.

71 Ópera estrenada en París en 1805 y, cinco años más tarde, en Barcelona. En: Diario de Barcelona, 19-10-1810. 
ron científicos, profesores, hombres de letras y personas cultivadas en general de la época; y después, por el marasmo general que experimentaron la economía española y la hacienda estatal, que cortaron de raíz la mayor parte de los proyectos ilustrados. No obstante, hay que matizar esta visión catastrófica, al menos, en lo que respecta a la realidad cultural barcelonesa, que fue más optimista de lo que pudiera parecer: tras la guerra, se produjo un notable aumento del comercio de instrumentos y partituras, se incrementó la actividad musical, subió la demanda de profesores de música, se multiplicaron los talleres de construcción, aparecieron nuevos periódicos musicales e, incluso, la actividad editorial en general vivió un repunte importante, con la traducción al castellano de Chateaubriand, Scott, Goethe y Schiller.

El florecimiento del comercio de partituras a lo largo de la tercera etapa se advierte en la cantidad de anuncios de compraventa de partituras que aparecen en el Diario de Barcelona $^{72}$. Igual que en las anteriores etapas, fue habitual la circulación mixta de partituras impresas y manuscritas ${ }^{73}$, y solían comercializarse en los mismos puntos de venta. Así, el dinamismo en la venta de documentos impresos y manuscritos debe mucho a los libreros (que no solo vendían música), a los comerciantes especializados en la venta de material musical y a los particulares. Además, a pesar de la escasez de fuentes respecto a los copistas, el elevado número de anuncios referentes a la venta de papel pautado y las abundantes fuentes musicales manuscritas conservadas en las bibliotecas y archivos españoles constatan una producción y una comercialización importantes de partituras manuscritas, realizadas por músicos profesionales (como es el caso del profesor de música Pedro Pablo Claparols) o por copiantes profesionales. Como ejemplo de la actividad de compraventa de partituras manuscritas, véase el anuncio de un particular que en 1823 vendía "una colección de música manuscrita parar guitarra de los mejores autores, una vocal con acompañamiento del mismo instrumentos de las mejores óperas dadas en este coliseo" ${ }^{74}$.

72 El número de anuncios referentes al comercio de partituras asciende a 79 entre 1814 y 1834 , con una media de 3,85 anuncios por año, de los cuales, más de la mitad hacen referencia a la compraventa de partituras para piano (ya sea para piano solo o para piano y otros instrumentos). Cabe recordar que entre 1792 y 1808 la media anual de anuncios referentes al comercio de partituras es de 2,4, y entre 1808 y 1814 la media es de 1,9. Véase BRUGAROLAS BONET (2015): 297-305.

$73 \mathrm{Al}$ menos hasta 1850 , fecha a partir de la cual se impuso definitivamente la comercialización del impreso calcográfico. En: GOSÁLVEZ LARA (2014): 215-258.

74 Diario de Barcelona, 16-11-1823.

\section{Establecimientos especializados en música}

Una figura que hay que tener en cuenta en la venta de partituras fue el comerciante especializado en música, que en sus establecimientos también ofrecía instrumentos y otros productos musicales ${ }^{75}$. Tal como se ha comentado anteriormente, los primeros establecimientos especializados en música fueron las tiendas-taller surgidas hacia 1800 y regentadas por constructores de instrumentos; no obstante, a partir de 1815-1820, estas tiendas-taller dejaron paso a los establecimientos especializados en música de mayor capacidad comercial y mejor surtidos, como los de Francisco España Tercero, Francisco Bernareggi y Agustín Altimira o el de Mariano Coll (surgido hacia 1828$)^{76}$; y a partir de 1830 algunos de estos establecimientos musicales (que en la documentación de la época empiezan a aparecer como almacenes de música) se transformaron en destacados comercios con un alto volumen de negocio y una variedad de producto que les permitía copar el mercado musical más allá del barcelonés, como fue el caso del almacén musical del italiano Francisco Bernareggi.

De hecho, Bernareggi ${ }^{77}$ ejemplifica muy bien la situación descrita. Llegado a Barcelona hacia septiembre $1819^{78}$, empezó su actividad en 1820 con un pequeño taller a pie de calle, en el número 2 de la plaza de l'Oli, donde vendía instrumentos de viento construidos por él mismo ${ }^{79}$; un año más tarde traslada el taller a la calle Boria ${ }^{80}$ y en 1824 ya disponía de un pequeño establecimiento especializado en música, ubicado en el número 1 de la plaza del Ángel, en el que vendía sus instrumentos de viento, además de partituras, cuerdas romanas, papel pautado y material para la construcción de instrumentos de viento (marfil y ébano) ${ }^{81}$; a

75 Mientras que en Madrid está documentada la existencia de almacenes musicales desde finales de la década de 1780, en Barcelona se ha podido probar la existencia de este tipo de establecimientos comerciales desde 1800, si bien se conocían bajo el nombre de tienda o botiga de música. La primera referencia que se tiene de comercios especializados en música con la denominación de almacén de música es de 1830.

76 BRUGAROLAS BONET (2015): 258-259.

77 Con relación a la actividad en la construcción de instrumentos de viento de Francisco Bernareggi véase BORRÀS Y ROCA, 1 (Barcelona, 2001): 110-135. BORRÃS Y ROCA, EZQUERRO, 22/2, (Madrid, 1999): 53-86. BORDAS IBÁÑEZ (2004). Respecto a la actividad de compraventa de instrumentos musicales y a la de construcción de pianos de Francisco Bernareggi véase BRUGAROLAS BONET (2015): 254-263.

78 BORRÀS Y ROCA, EZQUERRO, 22/2, (Madrid, 1999): 53 86. BORDAS IBÁÑEZ (2004): 64-67.

79 Diario de Barcelona, 8-3-1820.

80 Repartiment i pagament per Indústria i Comerç, ACHB, fondo Municipal, sección Catastro, IX-6.

81 Diario de Barcelona, 10-2-1824 y 19-10-1824. 
partir de 1827, Bernareggi decidió incorporar a su negocio la venta y el alquiler de pianos ${ }^{82}$. A partir de 1830 , habiéndose consolidado como constructor, pues ostentaba el título de Constructor de Instrumentos de la Real Cámara de $\mathrm{Su}$ Majestad, y Constructor de Instrumentos del Conservatorio de Música María Cristina, Bernareggi trasladó su almacén y su taller de construcción de instrumentos a un espacio más grande, al número 8 de la calle Ancha, una de las mejores calles de la ciudad de Barcelona. En su nuevo almacén musical prosiguió con la venta de instrumentos de viento de su fábrica, con la compraventa de pianos, instrumentos de viento (de otros constructores) y de cuerda, ofrecía partituras manuscritas e impresas (algunas mediante suscripción), cuerdas, papel rayado, pianos, instrumentos de viento y de cuerda, y también suscripciones a periódicos musicales ${ }^{83}$ : "D. Francisco Bernareggi, instrumentista de Cámara de S. M. Y del Real Conservatorio, premiado en todas las exposiciones públicas de artes, avisa a los señores profesores, no solo de esta ciudad, si bien los de afuera, que dará los instrumentos, tanto los de su fábrica como los estranjeros, a precios los más equitativos. Asimismo se hallaran métodos de todos instrumentos, como también piezas sueltas para piano y canto; asimismo cuartetos y otras piezas de varios profesores, cuerdas romanas, violines superiores de los mejores fabricantes" 84 . De este modo, hacia 1834, Bernareggi se convirtió en un referente en el mercado musical barcelonés, puesto que supo aprovechar el dinamismo y la vitalidad de la sociedad española del primer tercio del siglo XIX, que demandaba cada vez más productos musicales y que contaba con un amplio público profesional y aficionado capaz de leer e interpretar música.

\section{Particulares}

En el comercio de partituras en esta tercera etapa fue relevante también el papel de los particulares, que solían ser músicos profesionales, como Juan Abella o como Ignacio Cascante (flautista del Teatro de la Santa Cruz, del número 39 de la calle Escudellers) o profesores de música, como

82 Diario de Barcelona, 30-8-1827 y 2-5-1827. No es casual que el italiano quisiese ampliar su negocio con dicho instrumento, puesto que en esas fechas el piano era el instrumento más demandado por los aficionados a la música). Por esas fechas, la ciudad de Barcelona contaba, con al menos 14 constructores de pianos (número muy elevado si se tiene en cuenta que su población en 1830 era de 130.000 habitantes), que necesitaban insertar sus productos en el mercado del comercio musical y, por tanto, tenían que utilizar diferentes vías de distribución, tales como los propios talleres de construcción o los establecimientos especializados en música, como es este caso.

83 Diario de Barcelona, 13-2-1832 y 24-6-1838.

84 Diario de Barcelona, 2-4-1834.
Ramón Vilanova (profesor de piano y canto) o Pedro Pablo Claparols (maestro de danza y piano, del número 8 de la calle de la Fruta), pero que también podían ser relojeros, militares, papeleros, sastres y carpinteros, según la documentación. Los particulares participaron activamente en la compraventa de partituras, tanto impresas como manuscritas: "En casa del relojero, frente Sta. Monica, se hallan de venta varias óperas de los más modernos para piano, y algunas piezas de dichas óperas para toda orquesta; también se encontraran varias piezas para guitarra, música militar y papel de música" 85 , o bien "el que quiera comprar música militar, sinfonías, conciertos de clarinete o de violín, cuartetos o dúos, que acuda al trompeta mayor de artillería volante, y le dará a precio equitativo" ${ }^{86}$. Además, se ha podido constatar que dado el elevado coste que tenían las partituras manuscritas e impresas para ciertos aficionados, algunos particulares ofrecían la posibilidad de intercambiar partituras: "Un aficionado a la música que tiene un surtido selecto de piezas, como preludios, libros de variaciones, sonatas y dúos, todo esto para flauta, muchos dúos para flageolet, y música para guitarra, sola y acompañada; el que a poco coste quiera hacerse con esta música tendrá que hacer un cambio por ella con otra de igual mérito aunque sea de distinto instrumento" $" 87$.

La intensa actividad comercial de partituras a manos de los particulares, tal como se advierte en la cantidad de anuncios insertados en el Diario de Barcelona ${ }^{88}$, evidencia que tuvo que haber en esta tercera etapa una enorme cantidad de música en circulación. Cabe añadir que el estudio de los repertorios que ofrece dichos anuncios arroja interesantes resultados. Más de la mitad de los anuncios insertados por los particulares, se compone básicamente de obras de autores del repertorio internacional (Haydn, Pleyel y Mozart) para distintas formaciones de cámara y de reducciones para piano solo, piano y voz, guitarra sola o bien guitarra y voz, de óperas o de sinfonías conocidas del momento de Rossini, Generali, entre otros; además, es una clara muestra de que la guitarra y el piano fueron los instrumentos más habituales entre los aficionados y los que, por tanto, tuvieron más presencia y difusión tanto en establecimientos públicos como en los espacios privados.

85 Diario de Barcelona, 6-1-1825.

86 Diario de Barcelona, 15-4-1819.

87 Diario de Barcelona, 6-3-1821.

88 Mientras que en la primera etapa la media anual de anuncios insertados por particulares en el Diario de Barcelona fue de 1,1, entre 1814 y 1834 fue de 1,6 . Véase también la nota número 72. 


\section{Libreros}

Fueron los libreros, sin duda, los que tuvieron un papel más activo en el comercio de partituras impresas y manuscritas entre 1814 y 1834 . Solían vender obras manuscritas e impresas previamente adquiridas en el extranjero (lo que supone una buena fuente de información acerca del conocimiento que se tenía en España de autores coetáneos foráneos) ${ }^{89}$, también las obras que los editores les dejaban en depósito en su tienda o bien vendían obras impresas por ellos mismos (o incluso reimpresas, como en el caso del librero Manuel Riera). Cabe decir que a lo largo de la primera mitad del siglo XIX la diferencia entre editor, impresor y librero es bastante difusa, puesto que a menudo una misma persona desempeñaba los tres oficios. La figura más importante era la del impresor, puesto que un taller de impresión no se improvisaba; en cambio, un librero que únicamente vendía libros podía cambiar de sitio cuando quisiera; la figura del editor era más marginal y apenas se anunciaba puntualmente cuando se trataba de una persona diferente a la del impresor. La mayor parte de los libreros que se mencionan más adelante reunían las tres figuras en una sola persona, es decir, eran editores porque costeaban la publicación, eran impresores porque la materializaban en su taller de impresión y, finalmente, eran libreros y la vendían en su establecimiento.

Los anuncios de compraventa de partituras insertados en el Diario de Barcelona por los libreros permite afirmar que existió y fue habitual en Barcelona un comercio mixto de documentos impresos y manuscritos ${ }^{90}$, que "con frecuencia figuraban las mismas personas trabajando en ambas modalidades y, además, ambos tipos de publicaciones solían comercializarse en los mismos puntos de venta [en las mismas librerías]"91. Dichos anuncios también aportan datos referentes a los géneros musicales y a los compositores más populares de la época. Son especialmente abundantes las obras escritas para distintas formaciones de cámara, así como las reducciones (sobre todo para piano solo, y para guitarra sola) de óperas o de sinfonías conocidas del momento y las obras de repertorio popular para los instrumentos solistas más difundidos del momento (piano y guitarra). Los compositores más ofertados y demandados eran muy diversos, desde italianos (como Pucitta, Pacini y Rossini), pasando por los de corte germánico (como Mozart y Haydn),

89 Véanse los anuncios del Diario de Barcelona siguientes: 3-11-1816 y 4-9-1826.

90 La librería de Joaquín Mayol, en la calle Escudellers, anuncia tanto la venta de piezas impresas (Diario de Barcelona, 4-9-1826) como de piezas manuscritas (Diario de Barcelona, 16-11-1828).

91 GOSÁLVEZ LARA, 2014: 215-258. hasta otros extranjeros de moda en Europa (como Kozeluch, Steibelt, Clementi y Pleyel), sin faltar autores españoles, como Sor y Carnicer.

Hacia 1825, en Barcelona, que contaba con una población de 120.000 habitantes, se estima que estaban activos alrededor de 42 libreros, de los cuales 12 incorporaron a su negocio del libro la compraventa de partituras e incluso de papel pautado (como fue el caso del librero Thomas Gorchs). Los libreros más activos entre 1814 y 1830 fueron Juan Dorca $^{92}$, en la calle Escudellers; Sierra y Martí193 en la plaza Sant Jaume; Tomás Gaspar ${ }^{94}$, en la calle Baxada de la cárcel; Manuel Riera, en la calle Escudillers; Francisco Piferrer ${ }^{95}$, en la plaza del Ángel; y Tomás Gorchs ${ }^{96}$, entre otros. De algunos de estos profesionales se ha podido documentar la actividad musical que llevaron a cabo.

En primer lugar cabe destacar al librero e impresor del número 5 de la calle Escudillers, Manuel Riera. Tal como se advierte en el Diario de Barcelona, la mayor parte de las partituras que comercializaba Riera eran impresas (aunque no se descarta que vendiera partituras manuscritas, de ello no hay constancia), bien en su taller, o bien importadas de París por algún agente comercial. De hecho, reimprimía partituras de autores coetáneos conocidos, como Fernando

92 Juan Dorca y Morera (i-1821), librero e impresor oriundo de Vic. Durante la guerra de la Independencia imprimió para la Junta Superior de Cataluña, por ejemplo, Instrucción de la Junta Preparatoria dirigida a facilitar en el Principado las elecciones de diputados para las Cortes ordinarias del año próximo 1813. En 1814 se instaló en Barcelona. Y a partir de 1817 se dedicó a la impresión y venta de obras teatrales y dramáticas en italiano y de partituras.

93 Antonio Sierra y Martí, librero e impresor. Hijo de Valerio Sierra, librero zaragozano que se casó con la hija de la conocida familia de impresores barceloneses Martí. Antonio Sierra tenía, como sus predecesores, la imprenta ubicada en la barcelonesa plaza Sant Jaume. Véase VERNEDA RIBERA (2012): 102.

94 Tomas Gaspar fue un librero e impresor activo desde 1800 hasta 1830. Su negocio se ubicaba en la calle Baxada de la Cárcel.

95 Respecto a Juan Francisco Piferrer cabe añadir que fue miembro de una de las famílias de libreros e impresores más importantes de Barcelona de la segunda mitad del siglo XVIII y del primer tercio del siglo XIX. Los Piferrer ostentaban, desde 1763, el título de Impresor Real, así como el de Impresor del Santo Oficio de la Inquisición; a lo largo de dos generaciones trabajaron para la Real Audiencia, la Secretaría de Palacio, la Administración de Intendencia, la Administración General de Rentas, la Tesorería principal, el Palacio Episcopal y para el Ayuntamiento de Barcelona. Además del comercio local y comarcal, Juan Francisco Piferrer participó en un mercado regional y otro exterior. De este último, se importaron libros. Están documentados los contactos comerciales con los hermanos Tournes en Lyon y Ginebra, y con los Cramer ginebrinos a través de su corresponsal Bonnardel, que a su vez mantenía un activo comercio con Lisboa. En la capital lusa, Francisco Roberto fue su proveedor. En Italia, compraba a J. Anton Mabbi (Turín), J. Rocchi (Lucca) y Nicolas Pezzana (Venecia). BURGOS, PEÑA, 6 (1987): 181-216.

96 Véase nota número 35. 
Sor, que compraba en París y luego vendía en su tienda: "Cuadernito de música que contiene seis pequeñas piezas para guitarra, compuestas en París por Sor y reimpreso en esta ciudad por Manuel Riera" ${ }^{97}$. Se conservan, al menos, dos ejemplares de partituras publicadas (quizá impresas) por Riera. Por una parte, seis valses para guitarra arreglados por Domingo Daydí, basados en las óperas de Rossini La pietra del paragone, Elisabetta, L'inganno felice, L'italiana in Algeri y La Cenerentola, conservada en la Biblioteca Nacional de España ${ }^{98}$; seguramente fue publicada en 1817 o 1818, si se tienen en cuenta el año del estreno de la última de las óperas arregladas y el siguiente anuncio aparecido el 2 de mayo de 1818 en el Diario de Barcelona:

En la tienda [librería] de Manuel Riera, en los Escudellers, esquina que hace frente en la calle de Carabassa, se hallará de venta una colección de valses impresos, sacados de varias óperas del célebre Rossini, arregladas para guitarra por el señor Domingo Daydi. Igualmente unas variaciones de guitarra arregladas para forte-piano del señor Fernando Sor.

Por otra parte, se conserva en la Biblioteca de Catalunya una partitura publicada por Riera9 ${ }^{99}$. Se trata de un arreglo para guitarra realizado por Sebastián Pelegrí de la obertura que el compositor Ramón Carnicer escribió para la ópera El barbero de Sevilla de Rossini, la cual se tocó el día del estreno rossiniano en el Teatro de la Santa Cruz en 1818. La fecha de impresión de la partitura es imprecisa: puede ser del mismo año del estreno, o bien de un año más tarde, puesto que se anuncia en mayo de 1819: "Se vende cuaderno suelto, sinfonía de El barbero de Sevilla, música de D. Ramón Carnicer, arreglada para guitarra por D. Sebastián Pelegrí a 10 rs. vn." ${ }^{100}$. La librería de Manuel Riera, a partir de enero de 1819, fue la encargada de gestionar la suscripción de la segunda serie de uno de los primeros periódicos musicales españoles, La Lira de Apolo, que había empezado a publicarse en Madrid en octubre de $1817^{101}$. La última noticia que se tiene de la actividad comercial de Riera es un anuncio aparecido en agosto de 1820 en el Diario de Barcelona, en el que se detalla la venta de diferentes piezas impresas, to-

97 Diario de Barcelona, 18-4-1817.

98 Seis valses música de varias óperas del célebre maestro Rossini arregladas para guitarra por Domingo Daydi, Biblioteca Nacional de España (BNE), Mc/4197/8.

99 Sinfonia del Sr. Carnicer en la ópera El Barbero de Sevilla, Biblioteca Nacional de Catalunya (BC), M 428741.

100 Diario de Barcelona, 15-5-1819.

101 Únicamente precedido por el Periódico de Música (mayo de 1817) y el Diario de Damas (1805). das ellas arreglos para piano de óperas de Rossini (Armida, Otello y Ciro en Babilonia) a 12 reales de vellón cada una. Nótese que el precio de algunas de las partituras impresas que vendía Riera, a 10 o a 12 reales de vellón, es el mismo al que las vendía el librero Gorchs, este último casi tres lustros antes, en 1806. Probablemente, el hecho de que hacia 1820 hubiera aumentado la circulación de partituras impresas en España y el resto de Europa, debido al incremento de la producción y la demanda de estas, provocó el abaratamiento de los costes y, con ello, el mantenimiento de los precios de las partituras impresas.

En 1814 el librero e impresor Juan Dorca llega a Barcelona, procedente de Vic, y se instala en la calle Escudellers número 19, cerca de la librería de Riera y del taller de Francisco España Primero y Vantín Fabrés. Se encargará de imprimir y publicar los libretos de las óperas en italiano que se programan en el Teatro de la Santa Cruz, por lo cual decide italianizar su nombre (Giovanni Dorca). También en su librería se podía hallar cuadernos de música impresa, según se anuncia el Diario Político y Mercantil de Barcelona el 24 de octubre de 1815 , y a partir del 1 de mayo 1817 publicó la primera serie (que se desarrolla hasta finales del mes de setiembre de 1819) del Periódico de Música, un periódico musical impulsado por la Asociación de Accionistas para las Mejoras del Teatro (Teatro de la Santa Cruz), el primero de este tipo en Barcelona y que precede a La Lira de Apolo, aparecido en Madrid en octubre de 1817. El Periódico de Música se publicaba todos los meses, seis números cada vez, constando cada número de 24 páginas en pliegos de marquilla. Se podía adquirir mediante suscripción previa en la librería de Giovanni Dorca adelantado la suma de 72 reales por el abono de tres meses ${ }^{102}$. El repertorio de este pionero periódico musical, que suele reflejar la moda en ese momento, consistía en obras musicales, generalmente reducciones para piano y voz, derivadas de música operística de los maestros Rossini, Carnicer, Orlandi y Generali ${ }^{103}$. Que se sepa, únicamente se conservan del Periódico de Música 32 piezas musicales en la Biblioteca Nacional de España. Tal como sugiere Calvo, las piezas musicales que se incorporaron a estas publicaciones periódicas fueron similares a las que se ofrecieron en los periódicos de otras capitales europeas de edición anterior a las españolas, y su periodicidad era mensual, igual que en los

102 Para conocer con más detalle las condiciones de suscripción, el repertorio y el público al cual iba dirigido, véase BRUGAROLAS BONET (2015).

103 Diario de Barcelona, 21-11-1817. Con relación al repertorio de las partituras que vendían los libreros mediante suscripción al $P e$ riódico de Música, véanse, entre otros, los siguientes anuncios: Diario de Barcelona, 21-11-1817, Diario de Barcelona, 1-8-1818 y Diario de Barcelona, 30-8-1827. 
periódicos musicales extranjeros ${ }^{104}$. Según la misma autora, una de las primeras publicaciones para piano de estas características fue el Diario de las Damas, publicado en Madrid hacia 1805 , y del que solo se tiene noticia mediante las consultas hemerográficas.

Otro de los libreros-impresores que actuó en Barcelona en esta tercera etapa fue Juan Francisco Piferrer. Según el catastro de impresores libreros de 1801, tenía casa y tienda en la plaza del Ángel ${ }^{105}$. Además tenía en propiedad cuatro almacenes, y otra librería arrendada al librero Juan Sellent, ubicada en la calle Baxada de la Cárcel. Disponía de un catálogo de partituras, lo que conduce a pensar que, al igual que Manuel Riera, pudo haber vendido partituras de impresión propia, pues tenía su taller de impresión en el número 1 de la plaza del Ángel de Barcelona. Del catálogo referido únicamente se tiene constancia hemerográfica y se desconoce la relación de piezas que pudo llegar a ofertar en él; de hecho, se ha resaltado esta información porque la forma en que Piferrer inserta la noticia en el Diario de Barcelona parece indicar que se trataba de una práctica habitual en su negocio, y quizá en el de otros libreros, puesto que con sus cinco locales satisfacía sin dificultad las demandas de sus compradores locales y las peticiones de remesas de libros que llegaban de todo el país; además, con su catálogo pretendía controlar las entradas y salidas de libros y partituras de sus almacenes: "En la librería de Piferrer se hallan las piezas de música siguientes: Adam, método para piano; Viguerie, método para piano dividido en cuatro cuadros; ópera de Mahomet para piano solo; oberturas de las óperas de Rossini para piano solo; Moses en Egipto. Todas las óperas de Rossini para piano y acompañamiento de violín [...]. En la misma estará de manifiesto el catálogo de las demás piezas de música”106.

Igual que Riera, Piferrer optó por publicar partituras mediante suscripción; esta fue una práctica habitual entre los editores y los libreros, que buscaban formas de favorecer y asegurar la venta de partituras. Tanto en su formato hebdomadario como en el mensual, la suscripción proporcionaba al editor unos ingresos por anticipado que le aliviaban la inversión previa, que disminuían el riesgo de pérdidas y que, por tanto, permitía rebajar los precios. De este modo, Piferrer gestionó, durante tres trimestres de 1826, la suscripción a la segunda serie del Periódico de Música.

Un librero que también utilizó con cierta frecuencia la suscripción como modo de venta de partituras fue Thomas Gorchs. En 1829 ofrecía una suscripción a una selección de

104 CUERVO CALVO (2012): 94-103.

105 Cadastre d'impresors llibreters del 1801, AHCB, Fondo Municipal, sección Catastro.

106 Diario de Barcelona, 11-9-1826. las mejores óperas italianas, en este caso cuatro piezas, por 6 reales de vellón al mes ${ }^{107}$. Si se tiene en cuenta que, hacia 1829, la entrada más barata del Teatro de la Santa Cruz rondaba los 4 reales de vellón y que el sueldo de un trabajador de una fábrica hacia 1830 oscilaba entre los 10 y los 12 reales de vellón al día ${ }^{108}$, se entiende que el precio de una suscripción mensual de partituras por 6 reales de vellón se lo podía permitir una inmensa mayoría de la población barcelonesa de 1830. Este sistema y la asequibilidad que comportaba facilitó la amplia difusión del repertorio de moda entre los aficionados barceloneses. He aquí el anuncio de 1829 en el que se avisa de la modalidad de adquisición por suscripción:

Colección de las mejores óperas italianas traducidas en verso español con arreglo a la letra y la música del original. La general aceptación que merecen hoy día en los principales teatro de España las óperas italianas y el gusto y el afán con que el público concurre a oírlas y verlas representar nos han estimulado a ofrecer al público una colección seguida de las mejores óperas italianas publicadas hasta el día, y que en los sucesivos se publicarán, para lo cual están ya traducidas hasta el número 21. Se publicarán de cuatro en cuatro, empezando por las que están ya en la prensa, y saldrán a la luz, a saber: El cruzado en Egipto, Torvaldo y Darlisca, Moisés en Egipto y El Turco en Italia. Se admiten suscripciones para estas cuatro por 6 rs. vn. en la librería de Tomás Gorchs $^{109}$.

Cabe decir que la actividad comercial relacionada con la música llevada a cabo por Gorchs iba más allá de la venta de partituras, puesto que también vendía biografías de los músicos más importantes del momento, como la de Rossini, que seguramente conseguía gracias a alguna red internacional de distribución o bien mediante algún corresponsal o agente comercial.

José Torner fue otro librero musical activo en esta tercera etapa, con librería y taller de impresión en la calle $\mathrm{Ca}$ pellans. Era un impresor-editor-librero que editaba las obras con estampaciones muy originales y que, sobre todo, publicaba obras pedagógicas, obras de moral femenina, obras musicales y libros de historia y literatura. Destaca El porqué de la música ${ }^{110}$, una obra musical de Tomás Ballester de Belmonte, decorada con una finísima calcografía, que representa al maestro Ballester en plena composición de Círculo

107 Diario de Barcelona, 15-4-1829.

108 SARASÚA (2006): 428-429.

109 Diario de Barcelona, 15-4-1829.

110 BALLESTER de BELMONTE (1824). 
musical, publicada en 1824 y sujeta a una férrea censura, debido a que aquel año, tras la experiencia del Trienio Liberal, Fernando VII y su régimen ejercieron una represión muy dura y estricta a todos niveles.

Los datos relacionados con el papel desempeñado por los libreros en la difusión de partituras y material musical vienen a apoyar la conjetura de que ante el débil crecimiento de la imprenta musical en España hasta la tercera década del siglo XIX, los libreros eran los profesionales que, sin tener una dedicación exclusiva al comercio musical, se dedicaban con mayor empeño a la distribución de las obras musicales manuscritas e impresas.

\section{CONCLUSIONES}

El comercio de partituras era, a finales del siglo XVIII, una actividad consolidada en Madrid y en muchas otras ciudades europeas, tal como han demostrado diversos investigadores. Había, sin embargo, una laguna respecto al caso de Barcelona, una laguna que el presente análisis espera haber resuelto: se ha documentado que en 1792, el librero Antonio Chueca comerciaba con partituras en Barcelona, y a partir de los numerosos nuevos datos aportados se puede concluir que, desde ese año en adelante, dicho comercio no hizo sino florecer, de modo que en pocos años Barcelona se convirtió en una plaza imprescindible para la compraventa y el alquiler de partituras y para el comercio musical en general a nivel español y europeo.

Hasta llegar al constructor y comerciante Francisco Bernareggi, que hacia 1834 contaba con uno de los almacenes musicales más importantes de la ciudad condal, no son pocos los vendedores de partituras impresas y manuscritas, la mayoría desconocidos hasta ahora, que se han podido documentar: copistas, como Ángel Valli y Lanqueña; libreros que decidieron incorporar a su negocio la compraventa de partituras o incluso, en algunos casos, desempeñar labores de edición e impresión de este tipo de producto, como Manuel Riera (activo a partir de 1817) Juan Dorca (a partir de 1814), Juan Francisco Piferrer (a partir de 1795) y Tomás Gorchs (activo desde finales del siglo XVIII); constructores de instrumentos que con el tiempo transformaron sus tallerestienda en establecimientos especializados en música, con un alto volumen de negocio y gran variedad de productos musicales, como fueron Francisco España Primero, Francisco España Tercero, Valentín Fabrés y Francisco Bernareggi; también decidieron vender partituras comerciantes cuyos negocios carecían de vinculación con la música, como el quincallero de la plaza del Ángel o el cobrero Joseph Jufiant; $\mathrm{y}$, finalmente, se ha documentado una importante actividad de distribución de partituras por parte de particulares, algu- nas veces anónimos, mientras que otras veces se ha podido averiguar la identidad y la profesión (solían ser músicos profesionales), como el violinista Luis Gambino, el profesor de canto y piano Ramón Vilanova, el flautista Ignacio Cascante, entre otros.

La variedad y el alto número de vendedores de partituras impresas y manuscritas evidencian la enorme cantidad de música que había en circulación, tanto en Barcelona como en España y Europa, y demuestran que la producción y el consumo de la música se intensificó a lo largo del primer tercio del siglo XIX. Además, la participación en el comercio internacional (Europa y América) de diversas librerías, como la de Piferrer o la de Dorca, y las repetidas referencias recogidas en el Diario de Barcelona a partituras importadas de París y Londres de otras librerías indican también claramente que Barcelona, igual que Madrid, formaba parte de una red europea de distribución de partituras.

El estudio detallado de los datos referentes al tipo de partituras que se vendían (impresas o manuscritas) y de los precios a los que se vendían permite concluir que durante el período de 1792 a 1814 la copia manuscrita circuló en mayor proporción y a un precio más bajo que la copia impresa (probablemente por la falta de imprentas y por el elevado coste de producción de los impresos), y que a partir de 1815 se fue incrementando progresivamente la producción y la venta de partituras impresas, al mismo tiempo que se mantenían las ventas de partituras manuscritas. Todo ello demuestra la existencia de una circulación mixta de documentos impresos y manuscritos en el mercado musical barcelonés al menos hasta 1850.

Sin duda, el aumento de la demanda y la producción de partituras contribuyó al mantenimiento de los precios, gracias al abaratamiento de los costes de su producción, pero los editores y los comerciantes de partituras recurrieron a diversas fórmulas que les permitiera aumentar sus ventas o asegurar sus beneficios, tales como el alquiler, la suscripción y el intercambio, que facilitaban la accesibilidad de las obras a sus clientes. Con relación a la suscripción cabe destacar que podía ser de forma directa a una partitura impresa (por ejemplo, la reducción para piano solo, o piano y voz, o bien para guitarra, de alguna ópera conocida y de moda, como las de Rossini), o bien se podía conseguir surtidos de piezas impresas mediante suscripción a un periódico musical, por ejemplo, el Periódico de Música, del cual se ha podido documentar que fue el primero de este tipo en Barcelona, que estuvo impulsado y promovido por la Asociación de Accionistas para las Mejoras del Teatro (Teatro de la Santa Cruz), y que su primera serie la imprimió y publicó el librero Juan Dorca.

Poco se sabía con relación a la creación, hacia 1800, de los primeros establecimientos musicales especializados 
en música en el caso de Barcelona, y no son pocos los nuevos datos aportados en este trabajo. Destacan las tiendastaller de los guitarreros Valentín Fabrés y Francisco España Primero, que vendían partituras, instrumentos, cuerdas para guitarras, violines y violonchelos, papel pautado e incluso tinta para los copistas. A partir de 1820, este tipo de establecimiento evolucionó y dio paso a los almacenes musicales, unos comercios de mayor capacidad en los que se vendía todo tipo de mercancía relacionada con la música: instrumentos nacionales y extranjeros de todo tipo, partituras, tratados y métodos musicales, papel pautado, accesorios y diversos materiales para la construcción de instrumentos. En 1834, el almacén de Francisco Bernareggi, que empezó su actividad de venta de partituras en 1824, se había convertido en el almacén musical de referencia en Barcelona y en uno de los más importantes de España.

\section{BIBLIOGRAFÍA}

Acker, Yolanda, Música y danza en el «Diario de Madrid» (1758-1808): noticias, avisos y artículos, Madrid, Centro de Documentación de Música y Danza del Instituto de las Artes Escénicas y de la Música, Ministerio de Cultura, 2007.

Baldelló, Francisco de Paula, La música en Barcelona, Barcelona, Librería Dalmau, 1943.

Ballester de Belmonte, Tomás, El porqué de la música, o sea primero elementos del noble arte de la música, y método fácil, Barcelona, Imprenta de José Torner, 1824.

Bernardó, Màrius y Marín, Miguel Ángel (eds.), Instrumental Music in Late Eighteenth-Century Spain, Kassel, Edition Reichenberger, 2014.

Bordas Ibáñez, Cristina, La producción y el comercio de instrumentos musicales en Madrid ca. 1770 - ca. 1870, Valladolid, Universidad de Valladolid, 2004 [Tesis doctoral inédita].

Borràs y Roca, Josep, "Constructors d'instruments de vent fusta a Barcelona entre 1742 i 1826", Revista Catalana de Musicologia, 1 (Barcelona, 2001), 93-156.

Borràs y Roca, Josep y Ezquerro, Antonio, "Chirimías en Calatayud. Principio y final de un proceso constructivo", Revista de Musicología, 22/2 (Madrid, 1999), 53-86.

Brugarolas Bonet, Oriol, "La construcción de pianos en Barcelona (1780-1808): los primeros constructores de pianos", Cuadernos de Música Iberoamericana, 21 (2011), 83-102.

Brugarolas Bonet, Oriol, El piano en Barcelona (17901849): construcción, difusión y comercio, Barcelo- na, Universidad de Barcelona, 2015 [Tesis doctoral inédita].

Burgos, Francisco Javier; Peña, Manuel, "Imprenta y negocio del libro en la Barcelona del siglo XVIII. La casa Piferrer", Manuscrits: revista d'història moderna, 6 (1987), 181-216.

Comas y Güell, Montserrat, La impremta catalana i els seus protagonistes a l'inici de la societat liberal (18001833), Barcelona, Universitat Autónoma de Barcelona, 2009.

Cuervo Calvo, Laura, El piano en Madrid (1800-1830): repertorio, técnica interpretativa e instrumentos, Madrid, Universidad Complutense de Madrid, 2012.

García Mallo, María Carmen, "La edición musical en Barcelona (1847-1915). Partituras impresas conservadas en la Biblioteca de Catalunya", Boletín de la Asociación Española de Documentación Musical, 9 (Madrid, 2002), 7-154.

García Mallo, María Carmen, "Peters y España: edición musical y relaciones comerciales entre 1868 y 1892 ", Anuario Musical, 60 (Barcelona, 2005), 116-167.

Gosálvez Lara, José Carlos, "Edición, impresión y comercio de música: Bartolomé Wirmbs”, Scherzo, 64/7 (Madrid, 1992), 133-137.

Gosálvez, José Carlos, La edición musical española hasta 1936, Madrid, Asociación Española de Documentación, 1995.

Gosálvez Lara, José Carlos, "Aproximación al estudio de la edición musical manuscrita en Madrid", en Màrius Bernardó y Miguel Ángel Marín (eds.), Instrumental Music in Late Eighteenth-Century Spain, Kassel, Edition Reichenberger, 2014, 215-258.

Kenyon de Pascual, Beryl, "Ventas de instrumentos musicales en Madrid durante la segunda mitad del siglo XVIII", Revista de musicología, 5/2 (Madrid, 1982), 309-323.

Kenyon de Pascual, Beryl, "Ventas de instrumentos musicales en Madrid durante la segunda mitad del siglo XVIII", Revista de musicología, 6/1-2 (Madrid, 1983), 299-308.

Kenyon de Pascual, Beryl, "Ventas de instrumentos musicales en Madrid durante la segunda mitad del siglo XVIII", Revista de musicología, 8/2 (Madrid, 1985), 303-321.

Lolo, Begoña y Gosálvez, José Carlos (eds.), Imprenta y edición musical en España (ss. XVIII-XX). Madrid, Universidad Autónoma de Madrid y Asociación Española de Documentación Musical, 2012.

López Guallar, Pilar, "Naturales e inmigrantes en Barcelona a mediados del siglo XIX", Quaderns d'Història, 11 (Barcelona, 2004), 69-92. 
Marín, Miguel Ángel, "Music-Selling in Boccherini’s Madrid", Early Music, 33/2 (Oxford, 2005), 165-177.

Marín, Miguel Ángel y Leza, José Máximo, “1780-1808: ecos hispanos del Clasicismo", José Máximo Leza (ed.), Historia de la música en España e Hispanoamérica. La música en el siglo XVIII, Madrid, Fondo de Cultura Económica, 2014, vol. 4, 439-552.

Molas Ribalta, Pere, Los gremios barceloneses del siglo XVIII. La estructura corporativa ante el comienzo de la Revolución Industrial, Madrid, Federación Española de Cajas de Ahorros, 1970.

Moll, Jaime, "Una bibliografía musical periódica de fines del siglo XVIII", Anuario Musical, 24 (Barcelona, 1969), 247-258.

Ortega Rodríguez, Judith, "Los copistas del rey: la transmisión de la música en la Corte española en la segunda mitad del siglo XVIII", en Màrius Bernardó y Miguel Ángel Marín (eds.), Instrumental Music in Late Eighteenth-Century Spain, Kassel, Edition Reichenberger, 2014, 147-182.

Pellisa y Pujades, Joan, Guitarres i guitarrers d'escola catalana. Dels gremis al modernisme, Barcelona, Amalgama Edicions, 2013.

Rasch, Rudolf (ed.), Music Publishing in Europe, 16001900. Concepts and Issues, Berlín, Berliner Wissenschafts-Verlag, 2004.
Sarasúa, Carmen, "Trabajo y trabajadores en la España del siglo XIX”, en Agustín González Enciso y José Manuel Matés Barco (eds.) Historia económica de Espa$\tilde{n} a$, siglos XIX y XX, Barcelona, 2006, 413-433.

Sobrequés y Callicó, Jaume, Història de Barcelona, Barcelona, Ajuntament de Barcelona y Enciclopèdia Catalana, 1993, vol. 5 .

Susaeta, Ignacio, La música en las fuentes hemerográficas del siglo XVIII español: referencias musicales en la Gazeta de Madrid, y artículos de música en los papeles periódicos madrileños, Madrid, Universidad Complutense de Madrid, 1993.

Vallugera Fuster, Anna, "Arte como motor económico y arte como demostración de poder. La configuración del mercado del arte catalán en la Barcelona de finales del siglo XVIII", en Víctor Mínguez (ed.), Las artes y la arquitectura del poder, Castellón de la Plana, Publicacions de la Universitat Jaume I, 2013, 1299-1317.

Verneda Ribera, Meritxell, L'art gràfic a Barcelona. El llibre il·lustrat. 1800-1843, Barcelona, Universidad Autónoma de Barcelona, 2012. 